Original Research Paper

\title{
Development and Application of Nanoparticle Technology in Herbal Drug Formulation: A Review
}

\author{
Roosma Hatmayana $^{1}$, Syafira Nabillah ${ }^{1}$, Yuditha Mutia Windy ${ }^{1}$, Noval ${ }^{1}$ \\ ${ }^{1}$ Department of Pharmacy, Faculty of Health, Sari Mulia University. Banjarmasin, Indonesia.
}

\section{Article History}

Received:

18.11.2021

Revised:

21.12.2021

Accepted:

27.12.2021

*Corresponding Author:

Roosma Hatmayana

Email:

roosmayn@gmail.com

This is an open access article, licensed under: $\mathrm{CC}-\mathrm{BY}-\mathrm{SA}$
Abstract: Formulations of Herbal medicine are continuously being developed to improve health and treatment through natural ingredients obtained from the surrounding environment with scientific evidence. Common problems in herbal medicine are bioavailability, solubility, absorption of active substances and low stability. Recently, it has become a development trend to enter the realm of nanoparticle technology to its application in herbal drug formulations. Nanoparticle technology is a technology of drug particles are made on the nanoscale $(10 \mathrm{~nm}-1000 \mathrm{~nm})$. Many studies have been carried out on the development and application of nanoparticle-based delivery technology containing natural ingredients, from these results nanoparticlebased delivery technology has succeeded in delivering these natural materials through certain mechanisms in increasing the activity and bioavailability of herbal medicinal compounds. Particles at the nanoparticle scale have distinctive physical properties compared to particles at a larger size, especially in increasing the amount and purpose of delivering drug compounds. Another advantage of nanoparticle technology is the potential to be combined with other technologies, thus opening up opportunities to produce more perfect and targeted delivery systems. Examples of nanotechnologies that can be used are polymer nanoparticles, solid lipid particles, magnetic nanoparticles, and others. The manufacture of preparations based on nanoparticle technology is an alternative in the manufacture of herbal medicines and it is hoped that the bioavailability and therapy produced in the body will be better.

Keywords: Herbal Drug, Nanoparticle, Nano Technology. 